This is the author's final, peer-reviewed manuscript as accepted for publication. The publisher-formatted version may be available through the publisher's web site or your institution's library.

\title{
Preliminary study on rotary ultrasonic machining of CFRP/Ti stacks
}

W. L. Cong, Z. J. Pei, C. Treadwell

\section{How to cite this manuscript}

If you make reference to this version of the manuscript, use the following information:

Cong, W. L., Pei, Z. J., \& Treadwell, C. (2014). Preliminary study on rotary ultrasonic machining of CFRP/Ti stacks. Retrieved from http://krex.ksu.edu

\section{Published Version Information}

Citation: Cong, W. L., Pei, Z. J., \& Treadwell, C. (2014). Preliminary study on rotary ultrasonic machining of CFRP/Ti stacks. Ultrasonics, 54(6), 1594-1602.

Copyright: (C) 2014 Elsevier B.V.

Digital Object Identifier (DOI): doi:10.1016/j.ultras.2014.03.012

Publisher's Link:

http://www.sciencedirect.com/science/article/pii/S0041624X14000857

This item was retrieved from the K-State Research Exchange (K-REx), the institutional repository of Kansas State University. K-REx is available at http://krex.ksu.edu 


\title{
Preliminary study on rotary ultrasonic machining of CFRP/Ti stacks
}

\author{
W.L. Cong ${ }^{*}$, Z.J. Pei \\ Department of Industrial and Manufacturing Systems Engineering, \\ Kansas State University, \\ Manhattan, KS 66506, USA \\ C. Treadwell \\ Sonic-Mill, 7500 Bluewater Road NW, \\ Albuquerque, NM 87121, USA
}

\section{Keywords:}

CFRP composite, Drilling, Grinding, Rotary ultrasonic machining, Stack, Titanium.

* Corresponding author. Tel.: +1 7855323729.

E-mail address: weilong@ksu.edu (W.L. Cong). 


\begin{abstract}
Reported drilling methods for CFRP/Ti stacks include twist drilling, end milling, core grinding, and their derived methods. The literature does not have any report on drilling of CFRP/Ti stacks using rotary ultrasonic machining (RUM). This paper, for the first time, reports a study on drilling of CFRP/Ti stacks using RUM. It also compares results on drilling of CFRP/Ti stacks using RUM with reported results on drilling of CFRP/Ti stacks using other methods. When drilling CFRP/Ti stacks using RUM, cutting force, torque, and CFRP surface roughness were lower, hole size variation was smaller, CFRP groove depth was smaller, tool life was longer, and there was no obvious Ti exit burr and CFRP entrance delamination. Ti surface roughness when drilling of CFRP/Ti stacks using RUM was about the same as those when using other methods.
\end{abstract}




\section{Introduction}

Due to the increase of fuel price and market competition, commercial aircraft needs to be lighter and manufactured more efficiently. A recent trend in the aircraft industry is to increase the use of composite materials [Ramulu et al., 2001; Kanirura, 2005]. In a newer generation of aircraft, such as Boeing 787, 50\% of the total weight was composites [Garrick, 2007; Boeing web; Kanirura, 2005].

In aircraft structure, CFRP composites were often used by stacking up with titanium (Ti) to form stacks [Kim et al., 2005]. Bolting and riveting are currently the preferred methods for fastening CFRP and Ti together in the aircraft assembly [Bennett, 1985, Ramulu et al., 2001; Kim and Ramulu, 2004; Ramulu et al., 2001; Massarweh et al, 1992; Shyha 2010; Lambert, 1979; Colligan, 1994; Denkena et al., 2008; Brinksmerier et al., 2007]. As a result, a large number of holes need to be drilled in CFRP/Ti stacks [Shyha 2010; Boeing web, Zitoune et al., 2010].

Reported drilling methods for CFRP/Ti stacks include twist drilling, end milling, core grinding, and their derived methods [Colligan, 1994; Denkena et al., 2008; Yagishita, 2008; Brinksmeier and Janssen, 2002; Garrick, 2007; Shyha et al., 2010; Kim et al., 2001; Ramulu et al., 2001; Kim and Ramulu, 2004, 2005, 2007; Kim et al.; 2005; Yagishita, 2008]. Using these methods, CFRP and $\mathrm{Ti}$ were usually drilled with different tools (of different geometries and materials) and different speeds and feedrates [Colligan, 1994]. For example, a three-step method was used in the Boeing Company: (1) Drilling CFRP with a diamond coated twist drill; (2) Drilling Ti with a 
carbide drill; (3) Reaming the hole with a carbide reamer [Colligan, 1994]. Diamond coated twist drills performed well in CFRP drilling, but they would not last long in Ti drilling, since a lot of heat generated in Ti drilling would degrade the diamond coating on the twist drills. Carbide twist drills performed well in Ti drilling but were worn out very fast in CFRP drilling [Margolis, 2006].

Shortcomings of these methods include high cutting force [Ramulu et al., 2001; Kim and Ramulu, 2005; Yagishita 2008; Shyha et al., 2010], large Ti burr [Kim et al., 2001; Ramulu et al., 2001; Kim and Ramulu, 2004; Kim and Ramulu, 2004; Kim and Ramulu, 2005; Kim et al., 2005 2007; Garrick 2007], groove in composite (the CFRP material near the interface between CFRP and Ti was overcut and a groove was formed) [Brinksmeier and Janssen, 2002; Yagishita 2008], composite delamination [Kim et al., 2001; Kim and Lee, 2005; Kim and Ramulu, 2005; Garrick 2007; Yagishita 2008; Shyha et al., 2010], large variation in hole size [Weiss, 1989; Kim et al., 2001; Garrick 2007], poor surface roughness [Kim et al., 2001; Ramulu et al., 2001; Kim and Ramulu, 2004; Shyha et al., 2010], long cycle time [Colligan 1994], high tool wear rate [Lambert, 1987; Ramulu et al., 2001; Brinksmeier and Janssen, 2002; Kim and Ramulu, 2004; Garrick 2007; Shyha et al., 2010], high cutting temperature [Weiss, 1989; Kim et al., 2001; Ramulu et al., 2001; Kim and Ramulu, 2004], clogging of drill flutes of twist drills [Weiss, 1989; Shyha et al., 2010], and residual stress in $\mathrm{Ti}$ [Zitoune et al. 2010]. Therefore, it is desirable to investigate alternative method in drilling of CFRP/Ti stacks that can reduce or eliminate these shortcomings. 
Rotary ultrasonic machining (RUM) is a nontraditional drilling method. Figure 1 illustrates the RUM process. The cutting tool is a core drill with metal-bonded diamond abrasives. During drilling, the rotating tool vibrates axially at an ultrasonic frequency and moves along its axial direction towards the workpiece. Pumped coolant through the core of the drill washes away the swarf and prevents the tool from jamming and overheating. RUM has been successfully used in drilling of Ti [Churi et al. 2005, 2006, 2007ab; Cong et al., 2011_Ti] and CFRP [Li et al. 2007; Cong et al, 2011, 2012ab] with low cutting force and surface roughness, long tool life, and negligible $\mathrm{Ti}$ burr and CFRP delamination. However, there are no reported studies on comprehensive comparison of drilling of CFRP/Ti stacks using RUM and other reported methods.

This paper reports a study on RUM of CFRP/Ti stacks. It also compares with reported results on drilling of CFRP/Ti stacks using other methods. There are four sections in this paper. Following this introduction section, Section 2 describes properties and size of CFRP/Ti stacks, experimental set-up and conditions, and measurement procedures. Section 3 presents and discusses experimental results. Finally, Section 4 draws conclusions.

\section{Experiments}

\subsection{Properties and size of CFRP/Ti stacks}

Each of the CFRP/Ti stacks used in this study were formed by joining a CFRP plate (108 $\mathrm{mm} \times 58 \mathrm{~mm} \times 14 \mathrm{~mm})$ and a Ti plate $(108 \mathrm{~mm} \times 58 \mathrm{~mm} \times 7 \mathrm{~mm})$ together using adhesive 
(Ultra Bond super glue, Permatex Inc., Solon, OH, USA). The CFRP was composed of carbon fibers and epoxy resin. Plain woven fabric of carbon fibers had an orientation of 0/90 degrees, as illustrated in Figure 2. The carbon fiber yarn in the woven fabric had a thickness of $0.2 \mathrm{~mm}$ and a width of $2.5 \mathrm{~mm}$. The CFRP contained 21 layers of fabric (42 layers of carbon fibers). The Ti was titanium alloy (Ti-6Al-4V). Material properties of CFRP and Ti are listed in Table 1 and Table 2, respectively.

\subsection{Experimental set-up}

Experiments were performed on a rotary ultrasonic machine (Series 10, Sonic-Mill, Albuquerque, NM, USA). The experimental set-up is schematically illustrated in Figure 3. It mainly consisted of an ultrasonic spindle system, a data acquisition system, and a coolant system. The ultrasonic spindle system was comprised of an ultrasonic spindle, a power supply, and a control panel. The power supply converted conventional $(60 \mathrm{~Hz})$ electrical supply to high-frequency $(20 \mathrm{kHz})$ electrical energy. This high-frequency electrical energy was converted into mechanical vibration by a piezoelectric converter. The vibration, after being amplified, was transmitted to the cutting tool, causing it to vibrate axially at the frequency of $20 \mathrm{kHz}$. The amplitude of ultrasonic vibration could be adjusted by changing the setting of output control of the power supply. The motor atop the ultrasonic spindle supplied the rotational motion of the tool and different speeds could be obtained by adjusting the motor speed controller. The data acquisition system, including dynamometer, charge amplifier, A/D convertor, and computer with 
software, was used for measurement of cutting force and torque. More details about this system will be described in Section 2.4 (measurement procedures). The coolant system was comprised of pump, coolant tank, pressure regulator, flow rate and pressure gauges, and valves. It provided coolant to the spindle and the interface of machining.

The cutting tools, as illustrated in Figure 4, were metal-bonded diamond core drills (NBR Diamond Tool Corp., LaGrangeville, NY, USA). The outer and inner diameters (OD and ID) of the cutting tools were $9.54 \mathrm{~mm}$ and $7.82 \mathrm{~mm}$, respectively, and tuning length was $45 \mathrm{~mm}$. The diamond abrasives had mesh size of $80 / 100$ and concentration of 100 . The metal bond was of B type.

\subsection{Experimental conditions}

Considering the limitations of the experimental set-up (for example, vibration frequency was fixed at $20 \mathrm{kHz}$ on the machine), only two input variables were changed in the experiments:

- Ultrasonic power: Percentage of power from ultrasonic power supply to control the ultrasonic vibration amplitude (from 0 to $60 \%$ with an interval of $20 \%$ );

- Tool rotation speed: Rotational speed of the cutting tool (from 3000 to $7000 \mathrm{rpm}$ with an interval of $1000 \mathrm{rpm})$.

In order to achieve good hole quality and maintain reasonable tool life, the optimal feedrate in RUM was below $0.05 \mathrm{~mm} / \mathrm{s}$ for Ti [Cong et al., 2011a], but $0.5 \mathrm{~mm} / \mathrm{s}$ for CFRP [Cong et al., 2011bc; 2012ab]. In this study, CFRP/Ti stacks were drilled with feedrate of $0.05 \mathrm{~mm} / \mathrm{s}$. The 
experimental conditions were listed in Table 3. Under each test condition, four drilling tests were conducted.

\subsection{Measurement procedures}

A dynamometer (Model 9272, Kistler Inc., Winterthur, Switzerland) was used to measure the cutting force in the axial direction and torque. The electrical signals from the dynamometer were amplified by a charge amplifier (Model 5070A, Kistler Inc., Winterthur, Switzerland) and then transformed into digital signals by an $\mathrm{A} / \mathrm{D}$ converter. After being processed by a signal conditioner, the digital signals were collected by a data acquisition card (PC-CARD-DAS16/16, Measurement Computing Corporation, Norton, MA, USA) on a computer with the help of Dynoware software (Type 2815A, Kistler Inc., Winterthur, Switzerland). The sampling rate was $20 \mathrm{~Hz}$. The measured cutting force fluctuated with time within a certain range, as illustrated in Figure 5. The maximum cutting force of the force-time curve was used to represent the cutting force for drilling of each hole. Similarly, the maximum torque of the torque-time curve was used to represent the torque for drilling of each hole.

Surface profilometer (Surftest-402, Mitutoyo Corporation, Kanagawa, Japan) was used to measure surface roughness of the hole surface and groove depth. Surface roughness was measured on the machined hole surface along the axial direction of the hole. The surface roughness reported in this paper was Ra (average surface roughness). Test range and cut-off length of surface roughness measurement were set at $4 \mathrm{~mm}$ and $0.8 \mathrm{~mm}$, respectively. Groove 
depth (CFRP material near the interface between CFRP and Ti were overcut and a groove was formed.) was measured on machined CFRP hole surface near the interface of CFRP and Ti. As illustrated in Figure 6, for both surface roughness and groove depth, four measurements were performed with $90^{\circ}$ between two adjacent measurements. Each measurement was repeated twice. For each hole, there were eight values and the average of these eight values was used.

Ti exit burr height, as illustrated in Figure 7, was measured using an optical microscope (Model BX51 Olympus Inc. Tokyo, Japan). The maximum value of Ti exit burr height around the hole was used in this study. The eyepiece of the microscope had a magnification of 10 and the objective lens had a magnification of 10. Thus, the total magnification was 100 .

Delamination factor [Tsao and Hocheng, 2004] was used to describe the degree of delamination of CFRP material at the entrance side. It was determined by $D_{\mathrm{d}} / D$. Figure 8 illustrates both $D_{\mathrm{d}}$ and $D . D$ is the hole diameter. $D_{\mathrm{d}}$ is the diameter of the smallest circle that encloses all the delamination area around the hole. $D_{\mathrm{d}}$ and $D$ were measured by a vernier caliper (model IP-65, Mitutoyo Corp., Kanagawa, Japan). Each measurement was performed once.

Hole size (diameter) variation measures the spread of hole diameter under the same test conditions for each method [Weiss. 1989]. In this paper, it is represented by the maximum hole diameter minus the minimum hole diameter among the holes drilled under each test condition. Hole diameters were measured using a vernier caliper (model IP-65, Mitutoyo Corp., Kanagawa, Japan). Similar to surface roughness and groove depth, four measurements were performed with $90^{\circ}$ between two adjacent measurements. Each measurement was repeated twice. For each hole, 
there were eight values of hole diameter and the average of these eight values was used.

Tool life was defined as the number of holes a tool could drill without resharpening. It was calculated by the following formula:

$$
\text { Tool life }=\frac{\text { Total weight of abrisive portion of the tool }}{\text { Average weight loss of the tool for one test }}
$$

The weight of abrasive portion is the difference between weight of new tool and weight of tool without abrasive portion. The weight loss was the difference in the tool weight before and after the test. To remove any residuals left on the tool, the tool was cleaned using methanol and acetone and then dried using a hand dryer before measurement. The weight of the tool was measured by a high accuracy scale (Model APX-200, Denver Instrument, Denver, CO, USA).

\section{Results and discussion}

\subsection{Cutting force}

Cutting force in RUM of CFRP/Ti stacks under all test conditions in this study ranged from 140 to $477 \mathrm{~N}$, with the median of $296 \mathrm{~N}$, as shown in Figure 9. Reported cutting force data (including minimum, maximum, and median values) in drilling of CFRP/Ti stacks using other methods are also presented in Figure 9. Reported investigations using other methods are summarized in Table 4. It can be seen that the minimum, maximum, and median cutting forces using RUM were lower than those using other methods. 


\subsection{Torque}

The minimum, maximum, and median values of torque in RUM of stacks were $0.3,1.37$, and $0.95 \mathrm{~N} \cdot \mathrm{m}$, respectively. As shown in Figure 10, these torque values were lower than those in drilling CFRP/Ti stacks or Ti/CFRP/Al stacks using other methods [Lambert, 1979; Shyha et al., 2010]. Drilling of Ti foils/graphite/Ti foils workpiece resulted in similar torque values to those obtained this study [Kim et al., 2005]. Please note that the thickness of Ti foils in Kim et al.'s study was about $0.1 \mathrm{~mm}$. In comparison, the thickness of the Ti workpiece in this study was 8 $\mathrm{mm}$.

\subsection{Surface roughness}

$\underline{\text { Figure } 11}$ compares surface roughness in drilling of CFRP/Ti stacks using RUM and other methods.

Surface roughness on CFRP hole surfaces drilled using RUM ranged from 0.3 to $1.29 \mu \mathrm{m}$ with the median of $0.635 \mu \mathrm{m}$. As shown in Figure 11(a), surface roughness values using RUM were lower than those using other methods.

Surface roughness on Ti hole surfaces drilled using RUM ranged from 0.39 to $3.4 \mu \mathrm{m}$ with the median of $1.02 \mu \mathrm{m}$. As shown in Figure 11(b), these values were similar to those using other methods [Kim et al., 2001ab; Ramulu et al., 2001abc]. In this study, the test range of $4 \mathrm{~mm}$, the recommended setting of the surface profilometer, was used in surface roughness measurement. However, the test range in surface roughness measurement in reported studies using other 
methods would be smaller, because the Ti workpiece thickness in these investigations was 3.1 $\mathrm{mm}$ (smaller than the $4 \mathrm{~mm}$ test range used in this study). Different surface roughness values might be obtained for the same surface if different test ranges were used [Bhushan, 2002].

\subsection{CFRP groove depth}

Figure 12 compares CFRP groove depth in drilling of CFRP/Ti stacks using RUM and other methods. The range of CFRP groove depth using RUM was from 5 to $30.78 \mu \mathrm{m}$ with the median of $35 \mu \mathrm{m}$. The median value of groove depth using carbide twist drills was $101.6 \mu \mathrm{m}$ [Weiss, 1989].

\subsection{Ti exit burr}

Figure 13 shows a top-view picture of the Ti exit side of a hole drilled using RUM. There was no observable burr. Figure 14 compares burr height in drilling of CFRP/Ti stacks using RUM and other methods. There was always burr using other methods.

\subsection{CFRP entrance delamination}

Figure 15 shows a top-view picture of the CFRP entrance side of a hole drilled using RUM. No entrance delamination could be observed.

Comparisons of CFRP entrance delamination in drilling of CFRP/Ti stacks (or CFRP plates) using RUM and other methods are shown in Figure 16. Since there was no entrance delamination in drilling of CFRP/Ti stacks using RUM, the delamination factor was one. However, CFRP 
entrance delamination was always observed using other methods. Note that some data in the figure were obtained from drilling of CFRP plates (not CFRP/Ti stacks).

\subsection{Hole size variation}

Comparisons of CFRP hole size variation in drilling of CFRP/Ti stacks using RUM and other methods are shown in Figure 17(a). CFRP hole size variation in RUM of CFRP/Ti stacks under all test conditions in this study ranged from 10 to $20 \mu \mathrm{m}$, with the median of $10 \mu \mathrm{m}$ which was smaller than those in other methods.

Comparisons of Ti hole size variation in drilling of CFRP/Ti using RUM and other methods are shown in Figure 17(b). CFRP hole size variation in RUM of CFRP/Ti stacks under all test conditions in this study ranged from 10 to $20 \mu \mathrm{m}$, with the median of $15 \mu \mathrm{m}$. It also can be seen that the minimum, maximum, and median cutting forces using RUM were smaller than those using other methods.

\subsection{Tool life}

Figure 18 compares tool life in drilling of CFRP/Ti stacks using RUM and other methods. About 250 holes could be drilled using RUM, while the numbers of holes a tool could drill without resharpening using other studies were much smaller, ranging from 4 to 20 [Lambert, 1987; Weiss, 1989; Ramulu et al., 2001a; Ramulu et al., 2001b]. 


\subsection{Cutting rate (hole material removal rate)}

Hole material removal rate was used to represent cutting rate. Figure 19 compares cutting rate (hole material removal rate) in drilling of CFRP/Ti stacks using RUM and other methods. Cutting rate $\left(3.56 \mathrm{~mm}^{3} / \mathrm{s}\right)$ using RUM was lower than some of those using twist drilling methods [Lambert 1979/1987, Weiss, 1989, Ramulu et al., 2001bc, Kim et al., 2005]. Please note that these twist drilling methods generated worse surface roughness, additional post drilling processes were need. It would decrease hole cutting rate. Drilling of CFRP/Ti stacks using RUM did not need any post drilling method and it's cutting rate $\left(3.56 \mathrm{~mm}^{3} / \mathrm{s}\right)$ was higher than those using the methods combining twist drilling / end milling and surface reaming $\left(2.47 \mathrm{~mm}^{3} / \mathrm{s}\right.$ for carbide twist drills and $1.72 \mathrm{~mm}^{3} / \mathrm{s}$ for TiAlN coated solid carbide end mills). To increase the cutting rate, Cong et al. [2013] reported using variable feedrate in RUM of CFRP/Ti stacks (feedrate of 0.5 $\mathrm{mm} / \mathrm{s}$ was used to drill CFRP and feedrate of $0.05 \mathrm{~mm} / \mathrm{s}$ was used to drill Ti). In their experiment, cutting rate was increased $7.47 \mathrm{~mm}^{3} / \mathrm{s}$ and other output variables did not show significant increase. This cutting rate was similar to other methods.

\section{Conclusions}

This paper reports a study on drilling of CFRP/Ti stacks using rotary ultrasonic machining (RUM). It compares cutting force, torque, surface roughness, CFRP groove depth, Ti exit burr height, CFRP entrance delamination, hole size variation, and tool life using RUM with those in the literature using other methods. The following conclusions can be drawn from this study: 
1. Compared with other methods for drilling of CFRP/Ti stacks, RUM resulted in lower cutting force and CFRP surface roughness, smaller groove depth and hole size variation, and longer tool life.

2. There was no obvious Ti exit burr and CFRP entrance delamination when using RUM to drill CFRP/Ti stacks.

3. Ti surface roughness in drilling of CFRP/Ti stacks using RUM was about the same as those using other methods.

\section{Acknowledgements}

The work was supported by the National Science Foundation through award CMMI-0900462. The authors gratefully extend their acknowledgements to N.B.R. Diamond Tool Corp. for supplying the diamond core drills.

\section{References}

[Boeing website] 787 Dreamliner Program Fact Sheet, available at: http://www.boeing.com/commercial/787family/programfacts.html, Accessed on June 24, 2012.

[Bhushan, 2002] Bhushan B., 2002, Introduction of Tribology, First edition, John Wiley \& Sons, Inc., Hoboken, NJ, USA.

[Brinksmeier and Janssen, 2002] Brinksmeier E., and Janssen R., 2002, Drilling of multi-layer composite materials consisting of carbon fiber reinforced plastics (CFRP), titanium 
and aluminum alloys, CIRP Annals - Manufacturing Technology, 51(1), pp. 87-90.

[Chung, 2010] Chung D.D.L., 2010, Composite Materials Science and Applications, Second edition, Springer-Verlag London Ltd., London, UK.

[Churi et al., 2005] Churi N.J., Li Z.C., Pei Z.J., and Treadwell C., 2005, Rotary ultrasonic machining of titanium alloy: a feasibility study. Proceedings of the 2005 ASME International Mechanical Engineering Congress and Exposition (IMECE 2005), Orlando, FL, USA, November 5-11, pp. 885-892,

[Churi et al., 2006] Churi N.J., Pei Z.J., and Treadwell C., 2006, Rotary ultrasonic machining of titanium alloy: effects of machining variables, Machining Science and Technology 10(3), pp. 301-321.

[Churi et al., 2007a] Churi N.J., Pei Z.J., and Treadwell C., 2007a, Rotary ultrasonic machining of titanium alloy (Ti-6Al-4V): effects of tool variables, International Journal of Precision Technology, 1(1), pp. 85-96.

[Churi et al., 2007b] Churi N.J., Pei Z.J., and Treadwell C., 2007b, Wheel wear mechanisms in rotary ultrasonic machining of titanium, Proceedings of the 2007 ASME International Mechanical Engineering Congress and Exposition (IMECE 2007), Seattle, WA, USA, November 11-15, pp. 399-407.

[Colligan, 1994] Colligan K., 1994, New tool drills both titanium and carbon composites, American Machinist, (10), pp.56-58.

[Cong et al., 2011a] Cong W.L., Pei Z.J., Feng Q., Deines T.W., and Treadwell C., 2011, 
Experimental study on cutting temperature in rotary ultrasonic machining, Proceedings of NAMRI/SME, 39, pp. 369-376.

[Cong et al., 2011b] Cong W.L., Pei Z.J., Deines T.W., and Treadwell C., 2011, Rotary ultrasonic machining of CFRP using cold air as coolant: feasible regions, Journal of Reinforced Plastics and Composites, 30(10), pp. 899-906.

[Cong et al., 2011c] Cong W.L., Feng Q., Pei Z.J., Deines T.W., and Treadwell C., 2011, Dry machining of carbon fiber reinforced plastic composite by rotary ultrasonic machining: effects of machining variables, Proceedings of the ASME 2011 International Manufacturing Science and Engineering Conference (MSEC), Corvallis, OR, USA, June 13-17, MSEC2011-50116.

[Cong et al., 2012a] Cong W.L., Pei Z.J., Feng Q., Deines T.W., and Treadwell C., 2012, Rotary ultrasonic machining of CFRP: a comparison with twist drilling, Journal of Reinforced Plastics and Composite, 31(5), pp. 313-321.

[Cong et al., 2012b] Cong W.L., Pei Z.J., Feng Q., Deines T.W., and Treadwell C., 2012, Rotary ultrasonic machining of carbon fiber reinforced plastic composites: using cutting fluid versus cold air as coolant, Journal of Composite Materials, 46(14), pp. 1747-1753.

[Cong et al., 2013] Cong, W.L., Pei, Z.J., Deines, T.W., Liu, D.F., and Treadwell, C., 2013, Rotary ultrasonic machining of CFRP/Ti stacks using variable feedrate, Composites Part B: Engineering, 52, pp. 303-310.

[Davim and Reis, 2003] Davim J.P., and Reis P., 2003, Drilling carbon fiber reinforced plastics manufactured by autoclave-experimental and statistical study, Materials and Design, 
24(5), pp. 315-324.

[Denkena et al., 2008] Denkena B., Boehnke D., and Dege J.H., 2008, Helical milling of CFRP-titanium layer compounds, CIRP Journal of manufacturing Science and Technology, 1(2), pp. 64-69.

[Garrick, 2007] Garrick R., 2007, Drilling advanced aircraft structures with PCD (Poly-Crystalline Diamond) Drills, AeroTech Congress \& Exhibition, Los Angeles, CA, USA, September 18-20.

[Guu et al., 2001] Guu Y.H., Hocheng H., Tai N.H., and Liu S.Y., 2001, Effect of electrical discharge machining on the characteristics of carbon fiber reinforced carbon composites, Journal of Materials Science, 36(8), pp. 2037-2043.

[Khashaba, 2004] Khashaba U.A., 2004, Delamination in drilling GFR-thermoset composites, Composite Structures, 63(3-4), pp.313-327.

[Kim and Lee, 2005] Kim G.W., and Lee K.Y., 2005, Critical thrust force at propagation of delamination zone due to drilling of FRP/metallic strips, Composite Structures 69 (2) 137-141.

[Kim and Ramulu, 2004] Kim D., and Ramulu M., 2004, Drilling process optimization for graphite/bismaleimide-titanium alloy stacks, Composite Structures, 63(1), pp. 101-114.

[Kim and Ramulu, 2005] Kim D., and Ramulu M., 2005, Cutting and drilling characteristics of hybrid titanium composite laminate (HTCL), 37th Proceedings of materials and processing technologies for revolutionary applications fall technical conference, Seattle, WA, USA, October 31 - November 3, pp. 1-8. 
[Kim and Ramulu, 2005] Kim D., and Ramulu M., 2005, Study on the drilling of Titanium/Graphite hybrid composites, ASME International Mechanical Engineering Congress and Exposition, Orlando, FL, USA, November 5-11, pp. 99-106.

[Kim and Ramulu, 2005] Kim D., and Ramulu M., 2005, Study on the drilling of titanium/Graphite hybrid composites, Journal of Engineering Materials and Technology, 129(3), pp. 390-396.

[Kim et al. 2001] Kim D., Ramulu M., and Garbini J., 2001, Hole quality in drilling of Graphite/Bismalemide-Titanium stacks, 33rd International SAMPE Technical Conference, Seattle, WA, USA, November 5-8, pp. 1315-1326.

[Kim et al., 2005] Kim D., Ramulu M., and Pedersen W., 2005, Machinability of titanium/graphite hybrid composites in drilling, Transactions of NAMRI/SME, 33, pp. 445-452.

[Lambert, 1987] Lambert B.K., 1987, Cutting and drilling of composite materials, The Carbide and Tool Journal, 19(5), pp. 31-34.

[Li et al., 2007] Li Z.C., Pei Z.J., Sisco T., Micale A.C., and Treadwell C., 2007, Experimental study on rotary ultrasonic machining of graphite/epoxy panel, ASPE Spring Topical Meeting on Vibration Assisted Machining Technology, Chapel Hill, NC, USA, April 16-17, pp. 52-57.

[Mallick, 1997] Mallick P.K., 1997, Composite Engineering Handbook, Marcel Dekker Inc., New York, NY, USA.

[Margolis 2006] Margolis D., Stacking the odds, Cutting Tool Engineering, (8), 74-80. 
[Quan and Sun, 2010] Quan Y., and Sun L., 2010, Investigation on drilling0induced delamination of CFRP with infiltration method, Advanced Materials Research, 139-141, pp. $55-58$.

[Ramulu et al., 2001] Ramulu M., Branson T., and Kim D., 2001, A study on the drilling of composite and titanium stacks, Composite Structures, 54(10), pp. 67-77.

[Sadat, 1995] Sadat, A.B., 1995, Delamination and other types of damage of graphite/epoxy composite caused by machining, American Society of Mechanical Engineers, Applied Mechanics Division, 208, pp. 41-52.

[Schwartz, 1992] Schwartz, M.M., 1992, Composite Materials Handbook, Second edition, McGraw-Hill, Columbus, OH, USA.

[Shyha et al., 2010] Shyha I.S., Soo S.L., Aspinwall D.K., Bradley S., Dawson S., and Pretorius C.J., 2010, Drilling of titanium/CFRP/Aluminum stacks, Key Engineering Materials, 447-448, pp. 624-633.

[Weiss, 1989] Weiss R.A., 1989, Portable air feed peck drilling of graphite composite, titanium and other materials in dissimilar combinations, FASTEC '89, Arlinton, Texas, USA, Octomber 4-6.

[Yagishita, 2008] Yagishita H., Comparing drilling and circular milling for hole making in bi-layer composite materials consisting of carbon fiber reinforced plastic (CFRP) laminates and titanium alloys, Transactions of NAMRI/SME, 36, pp. 17-24.

[Zitoune et al., 2010] Zitoune R., Krishnaraj V., and Collombet F., 2010, Study of drilling of 
composite material and aluminium stack, Composite Structures, 92(5), pp. 1246-1255. 
Table 1 Material properties of CFRP and its components.

\begin{tabular}{lcc}
\hline Property & Unit & Value \\
\hline Density of CFRP & $\mathrm{kg} / \mathrm{m}^{3}$ & 1550 \\
Hardness (Rockwell) & $\mathrm{HRB}$ & $70-75$ \\
Density of epoxy matrix & $\mathrm{kg} / \mathrm{m}^{3}$ & 1200 \\
Elastic modulus of epoxy matrix & $\mathrm{GPa}$ & 4.5 \\
Tensile strength of epoxy matrix & $\mathrm{MPa}$ & 130 \\
Poisson's ratio of epoxy matrix & & 0.2 \\
Density of carbon fiber & $\mathrm{kg} / \mathrm{m}^{3}$ & 1800 \\
Elastic modulus of carbon fiber & $\mathrm{GPa}$ & 230 \\
Tensile strength of carbon fiber & $\mathrm{GPa}$ & 5 \\
Poisson's ratio of carbon fiber & & 0.3 \\
Melting point of carbon fiber & ${ }^{\circ} \mathrm{C}$ & 3552 \\
\hline
\end{tabular}

Table 2 Material properties of titanium alloy (Ti-6Al-4V).

\begin{tabular}{lcc}
\hline Property & Unit & Value \\
\hline Density & $\mathrm{kg} / \mathrm{m}^{3}$ & 4510 \\
Hardness (Rockwell) & $\mathrm{HRC}$ & 36 \\
Elastic modulus & $\mathrm{GPa}$ & 113.8 \\
Tensile strength & $\mathrm{MPa}$ & 950 \\
Melting point & ${ }^{\circ} \mathrm{C}$ & 1660 \\
\hline
\end{tabular}

Table 3 Experimental conditions.

\begin{tabular}{ccc}
\hline $\begin{array}{c}\text { Feedrat } \\
\mathrm{e}\end{array}$ & Tool rotation & Ultrasonic \\
$(\mathrm{mm} / \mathrm{s})$ & $(\mathrm{RPM})$ & $\%$ \\
\hline & & 0 \\
& 4000 & 20 \\
& & 40 \\
0.05 & 2000 & 60 \\
& 3000 & \\
& 4000 & 40 \\
& 5000 & \\
\hline
\end{tabular}


Table 4 Summary of reported investigations.

\begin{tabular}{|c|c|c|c|}
\hline Reference & $\begin{array}{l}\text { Hole } \\
\text { diameter } \\
(\mathrm{mm})\end{array}$ & Tool type & $\begin{array}{l}\text { Thickness }(\mathrm{mm}) \text { and } \\
\text { material of workpiece }\end{array}$ \\
\hline [This study] & 9.6 & diamond core drills & 14 CFRP / 7 Ti \\
\hline [Lambert 1979] & 6.35 & carbide twist drills & $7.62 \mathrm{CFRP} / 12.7 \mathrm{Ti}$ \\
\hline [Weiss, 1989] & 6.35 & carbide twist drills & 6.35 CFRP / 6.35 Ti \\
\hline [Colligan, 1994] & 7 & coated twist drills & CFRP / Ti, unknown details \\
\hline [Kim et al., 2001a] & 6.35 & HSS twist drills & \multirow{3}{*}{ 7.62 CFRP / $3.1 \mathrm{Ti}$} \\
\hline [Kim et al., 2001b] & 6.35 & carbide twist drills & \\
\hline [Ramulu et al., 2001a] & 6.35 & HSS twist drills & \\
\hline [Ramulu et al., 2001b] & 6.35 & HSS twist drills & \multirow[t]{2}{*}{ 7.62 CFRP / $3.1 \mathrm{Ti}$} \\
\hline [Ramulu et al., 2001c] & 6.35 & carbide twist drills & \\
\hline [Davim and Reis, 2003a] & 5 & carbide twist drills & \multirow{2}{*}{3 CFRP } \\
\hline [Davim and Reis, 2003b] & 5 & carbide twist drills & \\
\hline [Khashaba, 2004a] & 8 & HSS twist drills & 3.52 GFRP \\
\hline [Khashaba, 2004b] & 8 & HSS twist drills & 7.15 GFRP \\
\hline [Kim et al., 2005] & unknown & carbide twist drills & Ti foils / Graphite / Ti foils \\
\hline $\begin{array}{l}\text { [Kim and Ramulu, } \\
\text { 2005/7] }\end{array}$ & unknown & carbide twist drills & Ti foils / Graphite / Ti foils \\
\hline [Garrick, 2007a] & 6.35 & coated twist drills & \multirow{2}{*}{$7.72 \mathrm{CFRP} / 6.15 \mathrm{Ti}$} \\
\hline [Garrick, 2007b] & 6.35 & carbide twist drills & \\
\hline [Denkena et al., 2008] & 8 & coated carbide end mills & 6 CFRP / $11 \mathrm{Ti}$ \\
\hline [Yagishita, 2008a] & 6 & carbide twist drills & \multirow{2}{*}{$4 \mathrm{CFRP} / 3 \mathrm{Ti}$} \\
\hline [Yagishita, 2008b] & 5 & coated carbide end mills & \\
\hline [Quan and Sun, 2010] & 4 & carbide twist drills & 3.5 CFRP \\
\hline [Shyha et al., 2010a] & 6.35 & carbide twist drills & \multirow{3}{*}{$30 \mathrm{Ti} / 30 \mathrm{CFRP} / 30 \mathrm{Al}$} \\
\hline [Shyha et al., 2010b] & 6.35 & coated twist drills & \\
\hline [Shyha et al., 2010c] & 6.35 & carbide twist drills & \\
\hline [Zitoune, et al., 2010] & $6 \& 8$ & carbide twist drills & 4.2 CFRP / $3 \mathrm{Al}$ \\
\hline
\end{tabular}




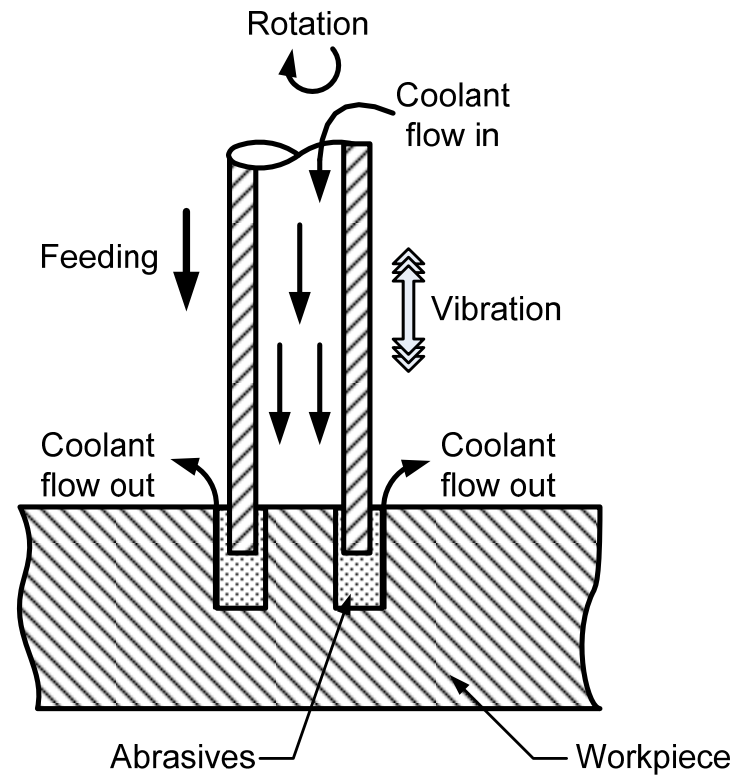

Figure 1 Illustration of rotary ultrasonic machining (RUM). 


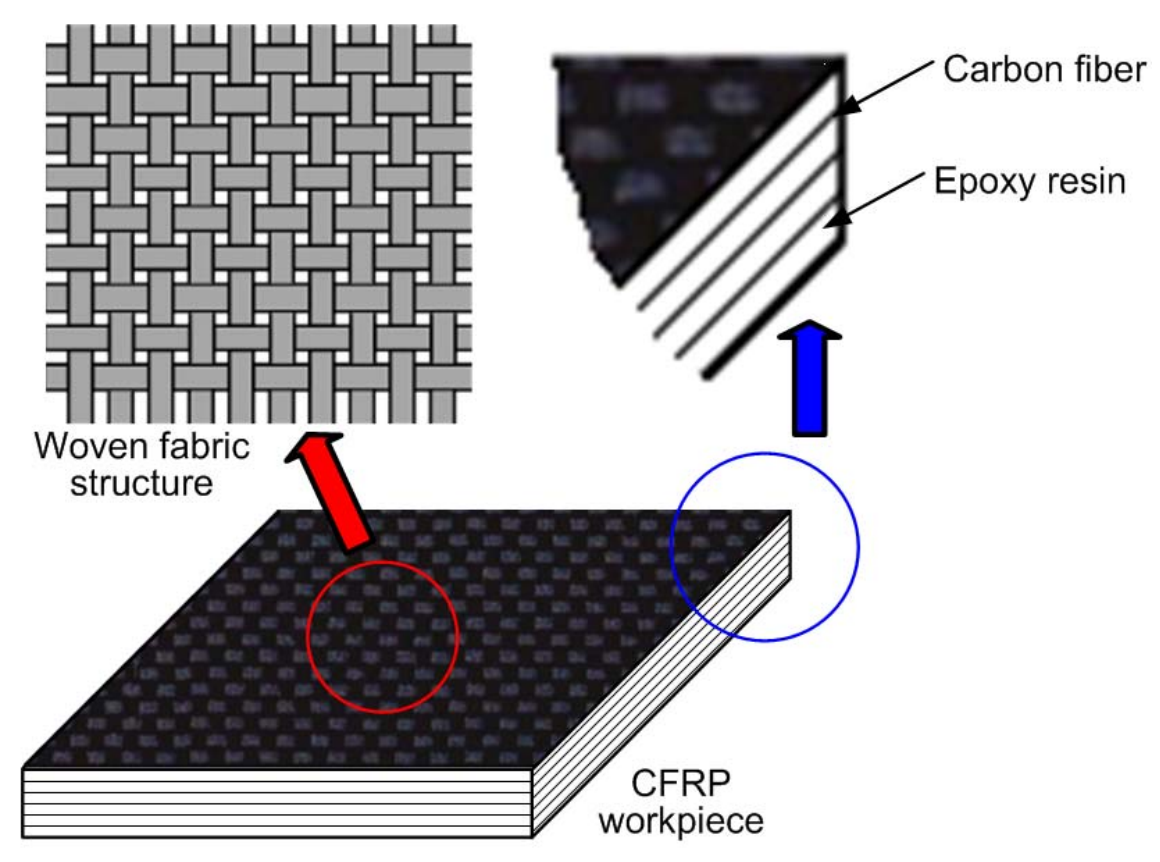

Figure 2 Illustration of woven fabric and CFRP structure. 


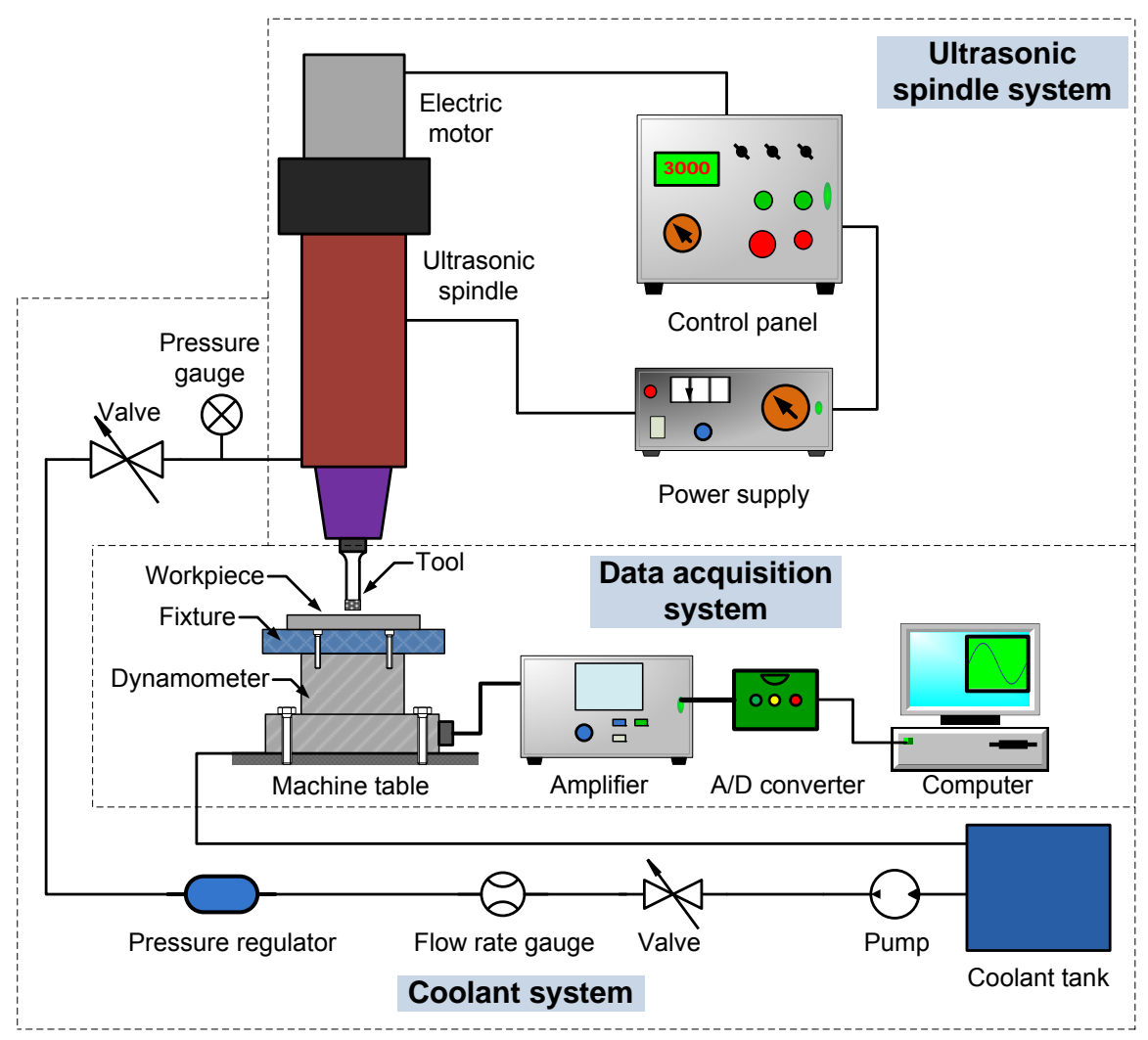

Figure 3 RUM experimental set-up. 


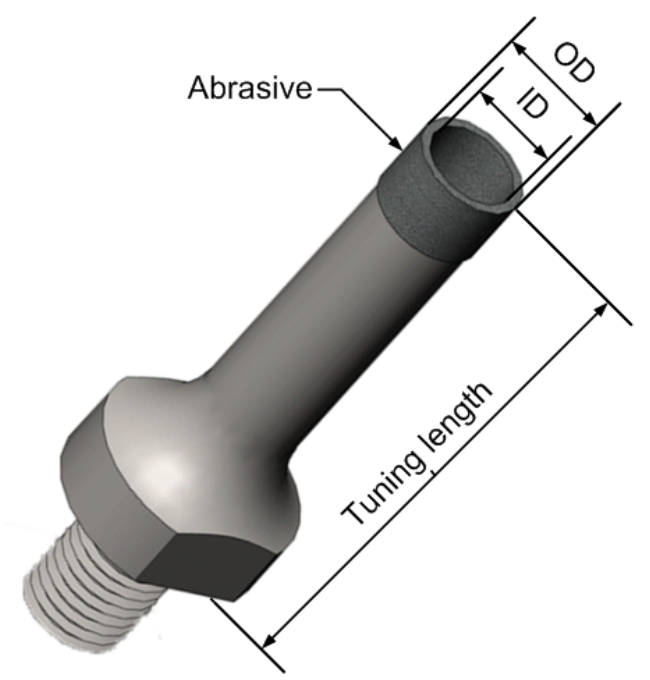

Figure 4 Illustration of RUM tool.

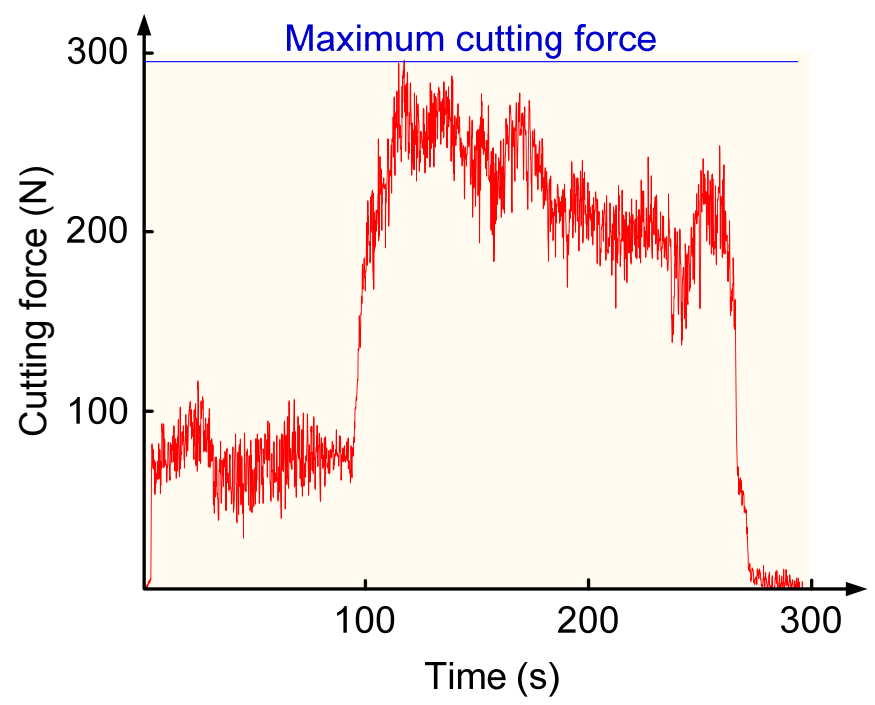

Figure 5 A typical cutting force and time curve. 

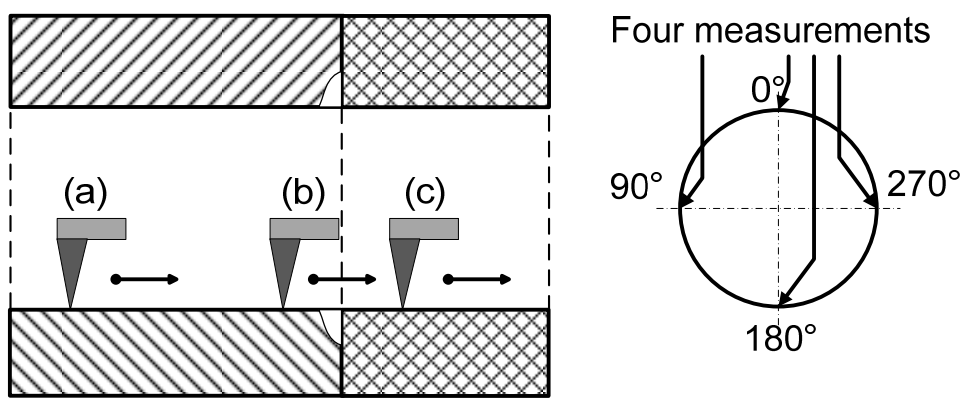

CFRP

$\mathrm{Ti}$

(a) CFRP surface roughness measurement

(b) CFRP groove depth measurement

(c) Ti surface roughness measurement

Figure 6 Surface roughness and groove depth measurements. 


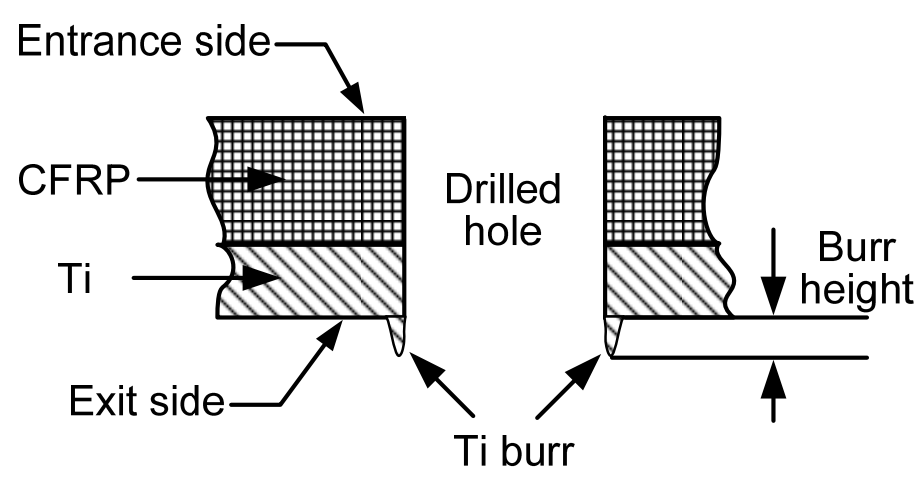

Figure 7 Illustrations of Ti exit burr and burr height.

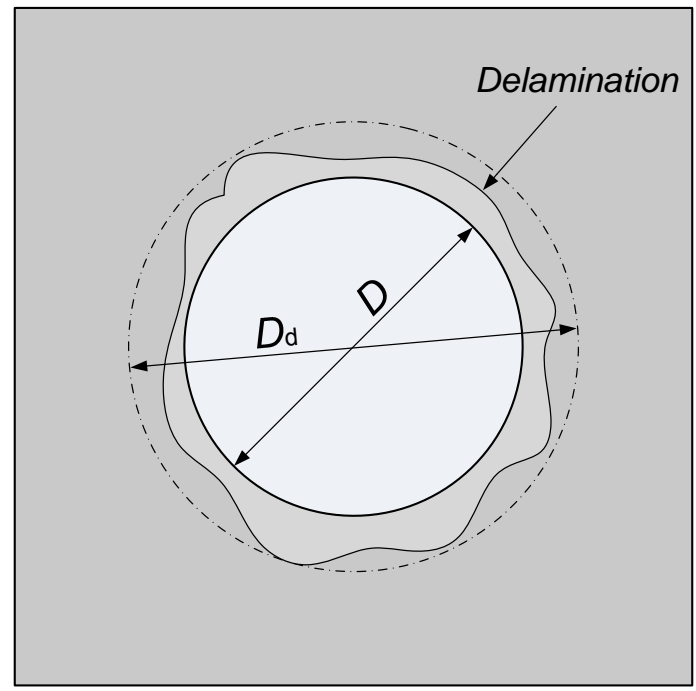

Figure 8 Measurement of delamination factor. 


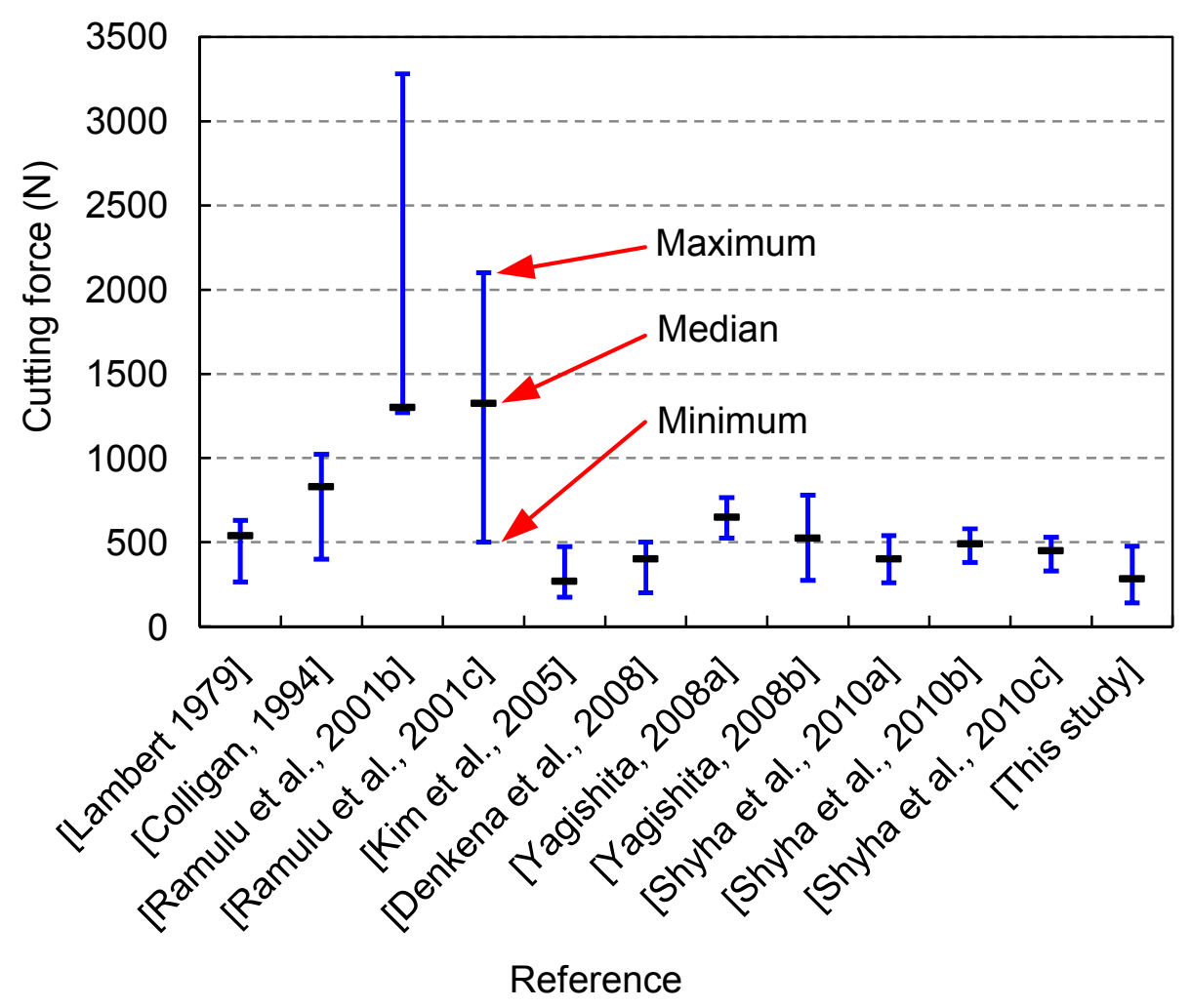

Figure 9 Comparison of cutting force. 


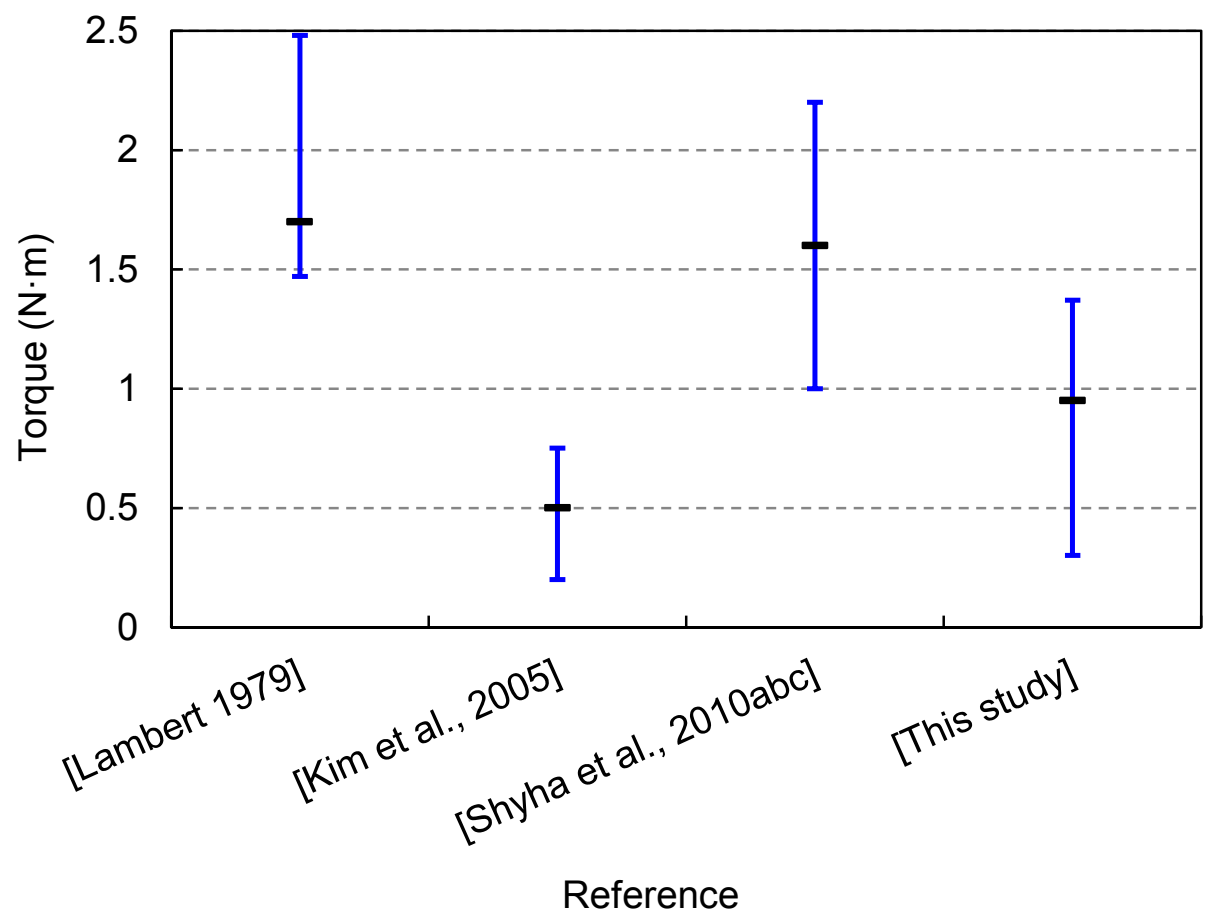

Figure 10 Comparison of torque. 


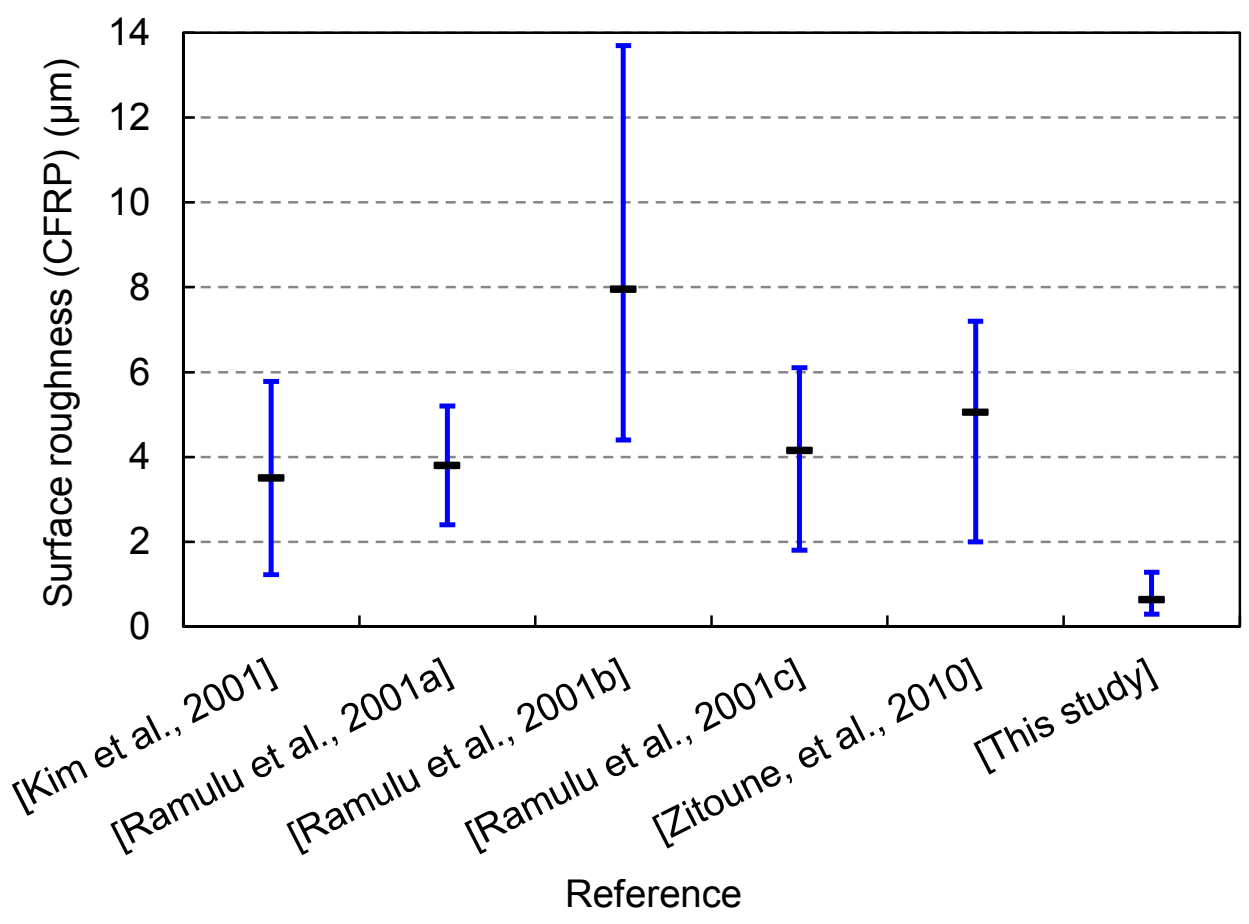

(a) On machined CFRP surface

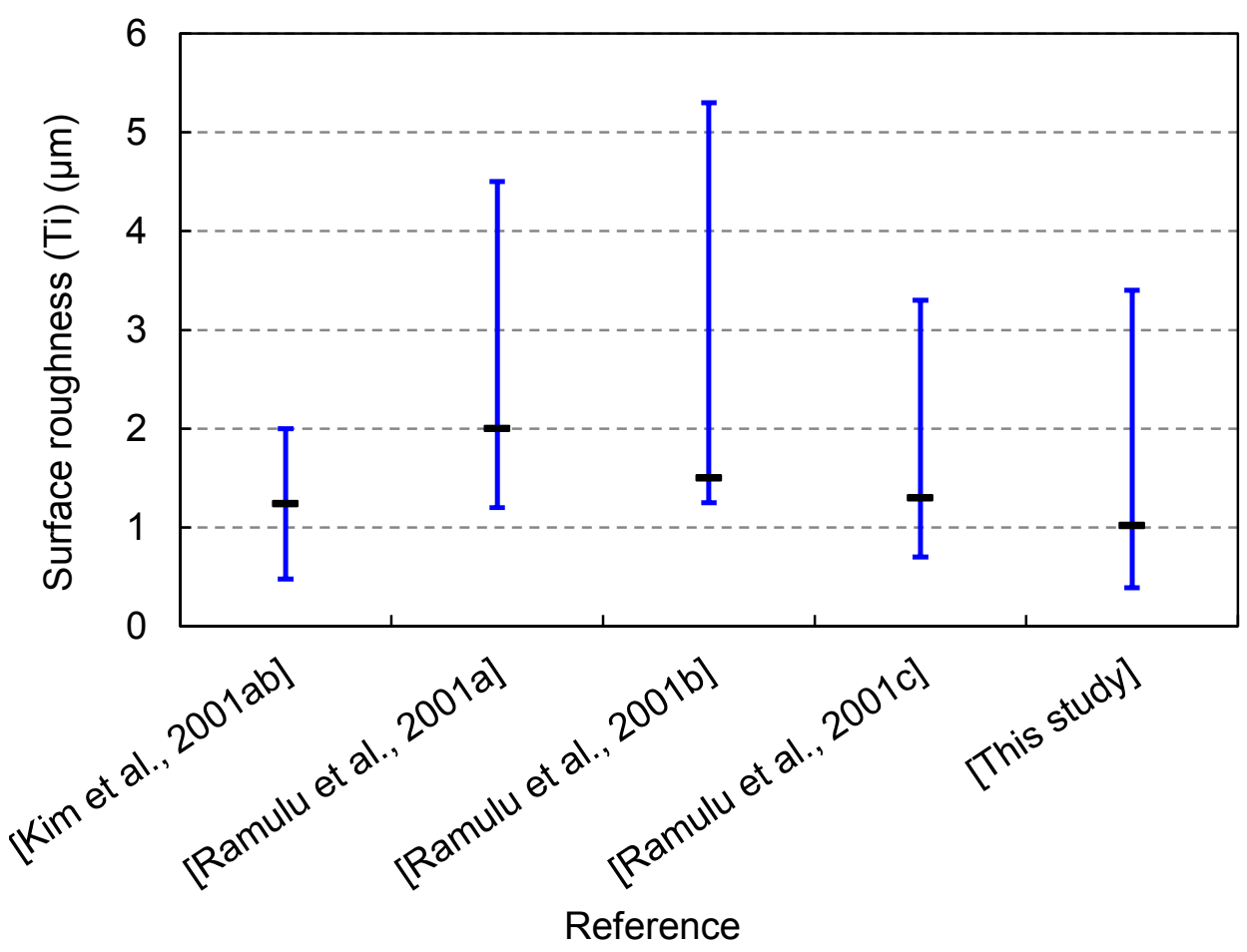

(b) On machined Ti surface

Figure 11 Comparison of surface roughness. 


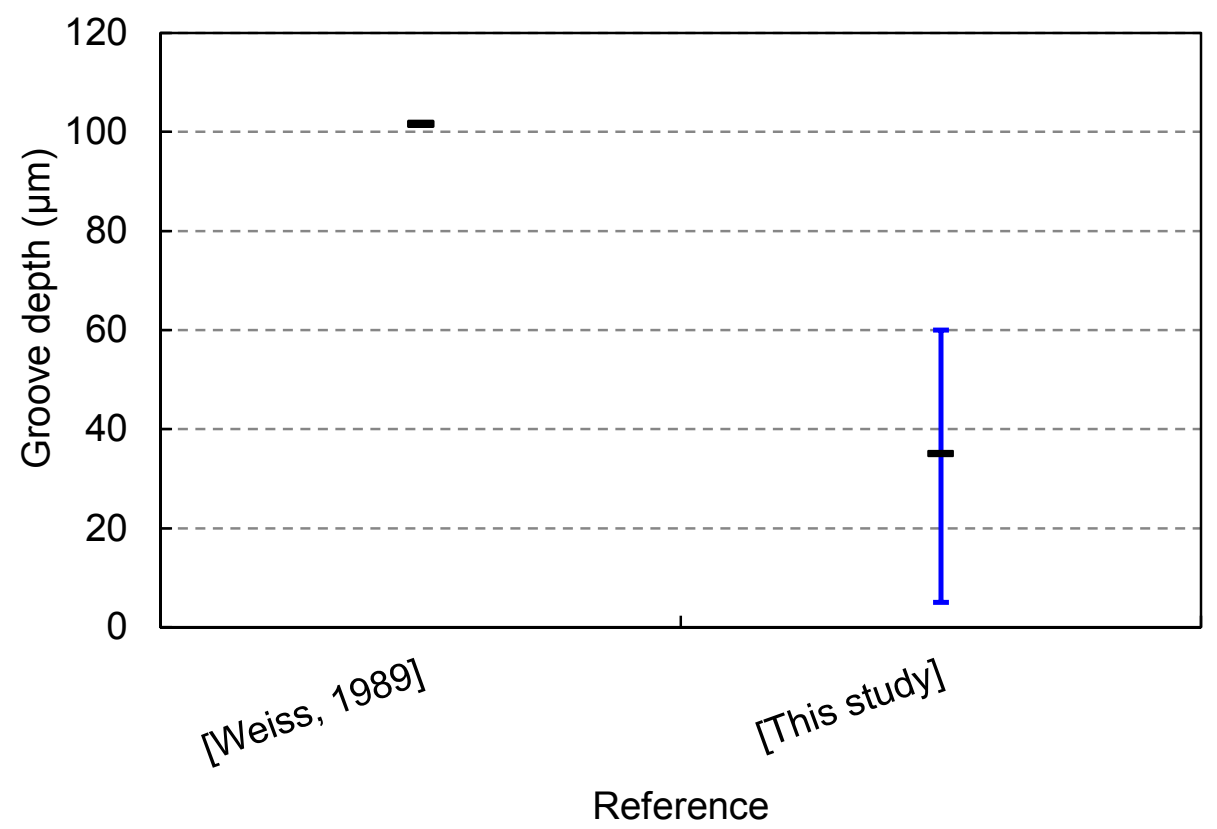

Figure 12 Comparison of CFRP groove depth. 


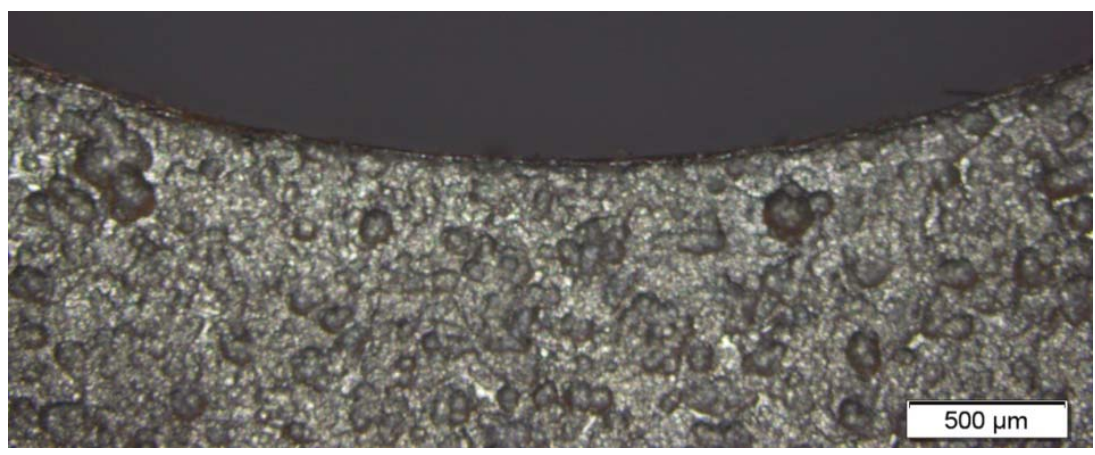

Figure 13 Top view of Ti exit side of a hole drilled using RUM.

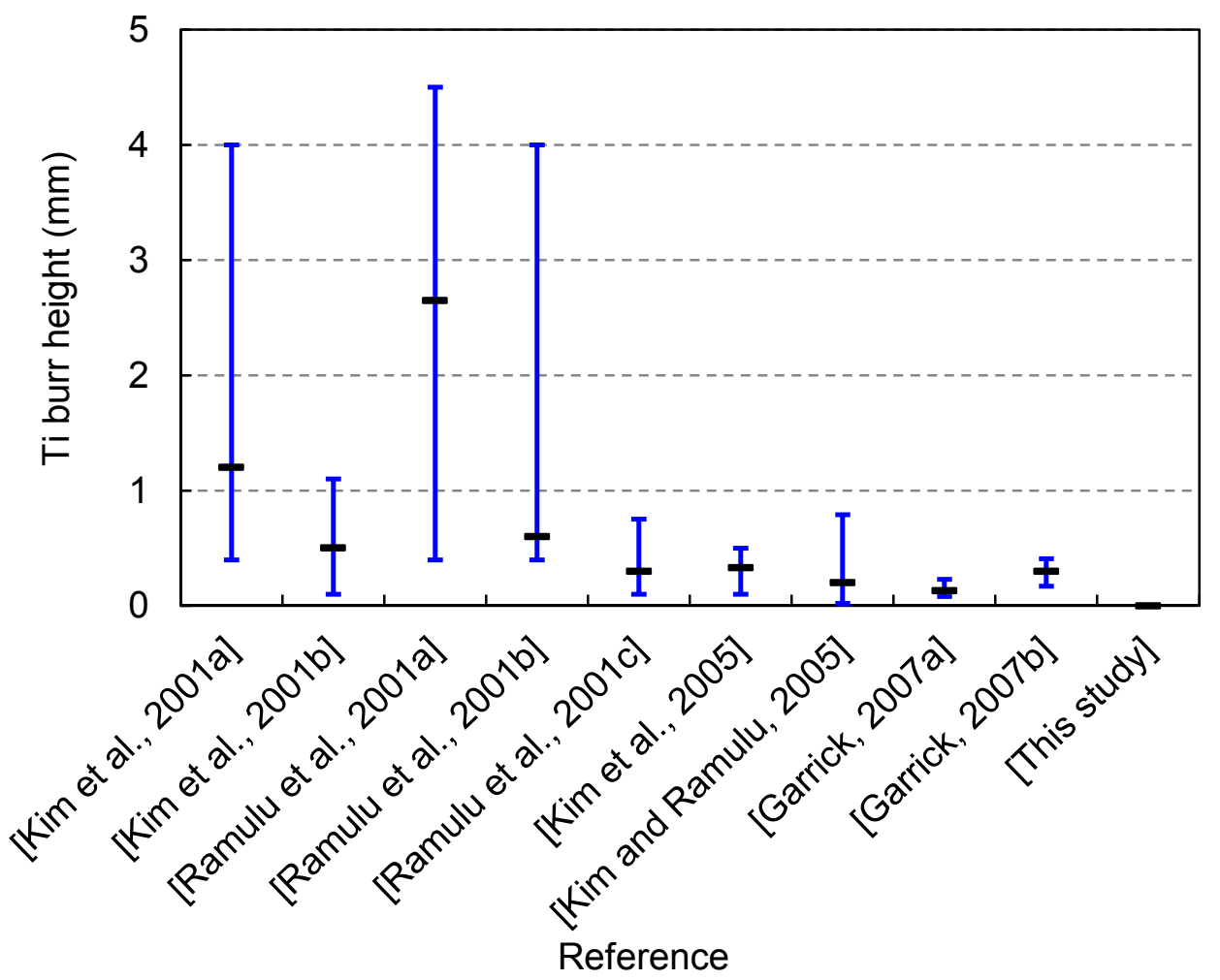

Figure 14 Comparison of Ti exit edge burr height. 


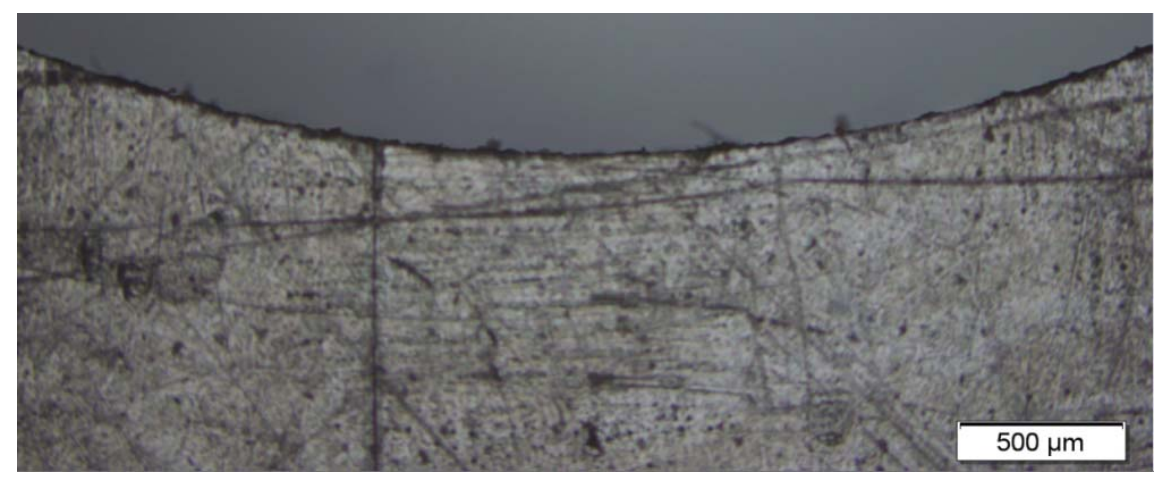

Figure 15 Top view of CFRP entrance side of a hole drilled using RUM.

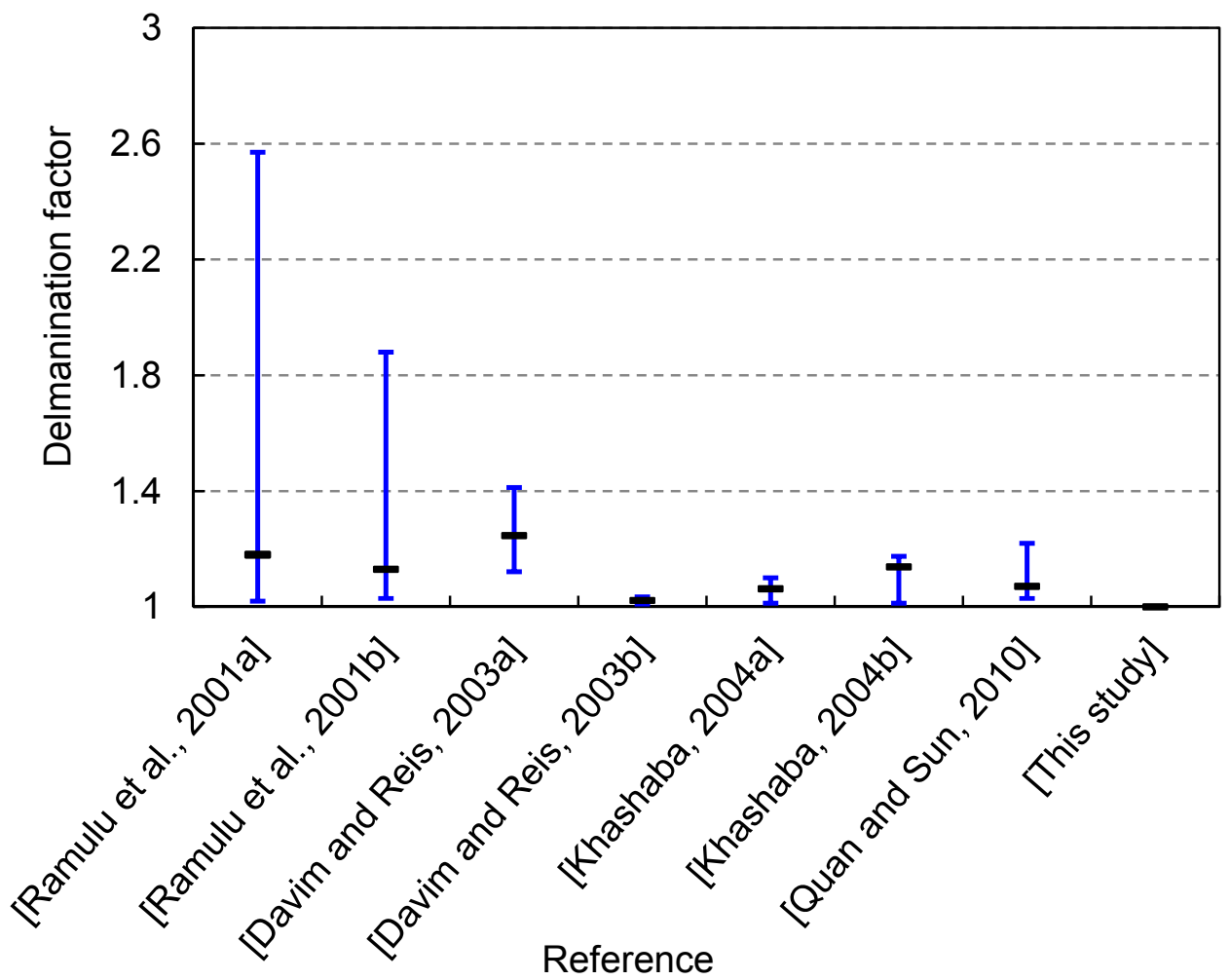

Figure 16 Comparison of CFRP entrance delamination. 


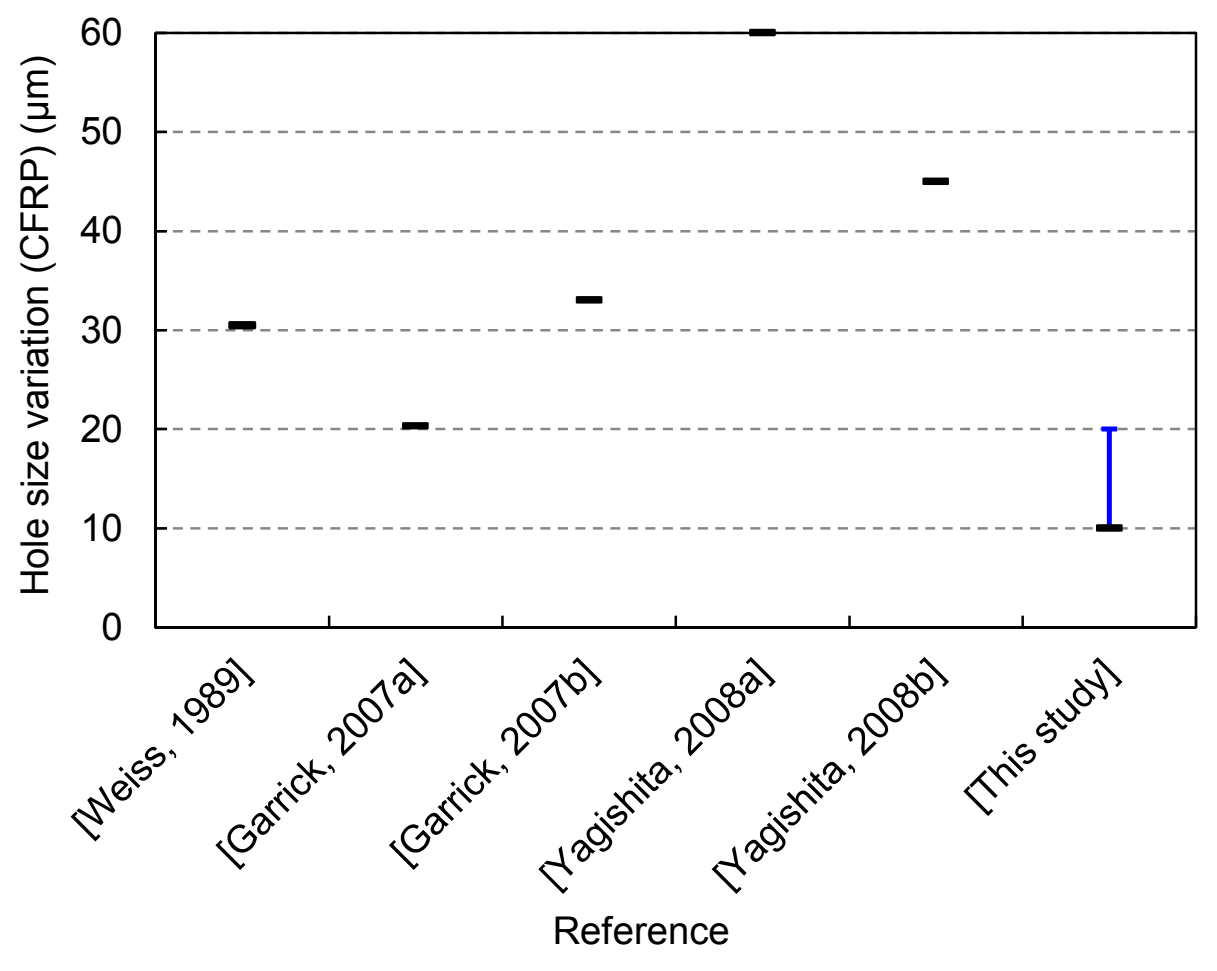

(a) For CFRP

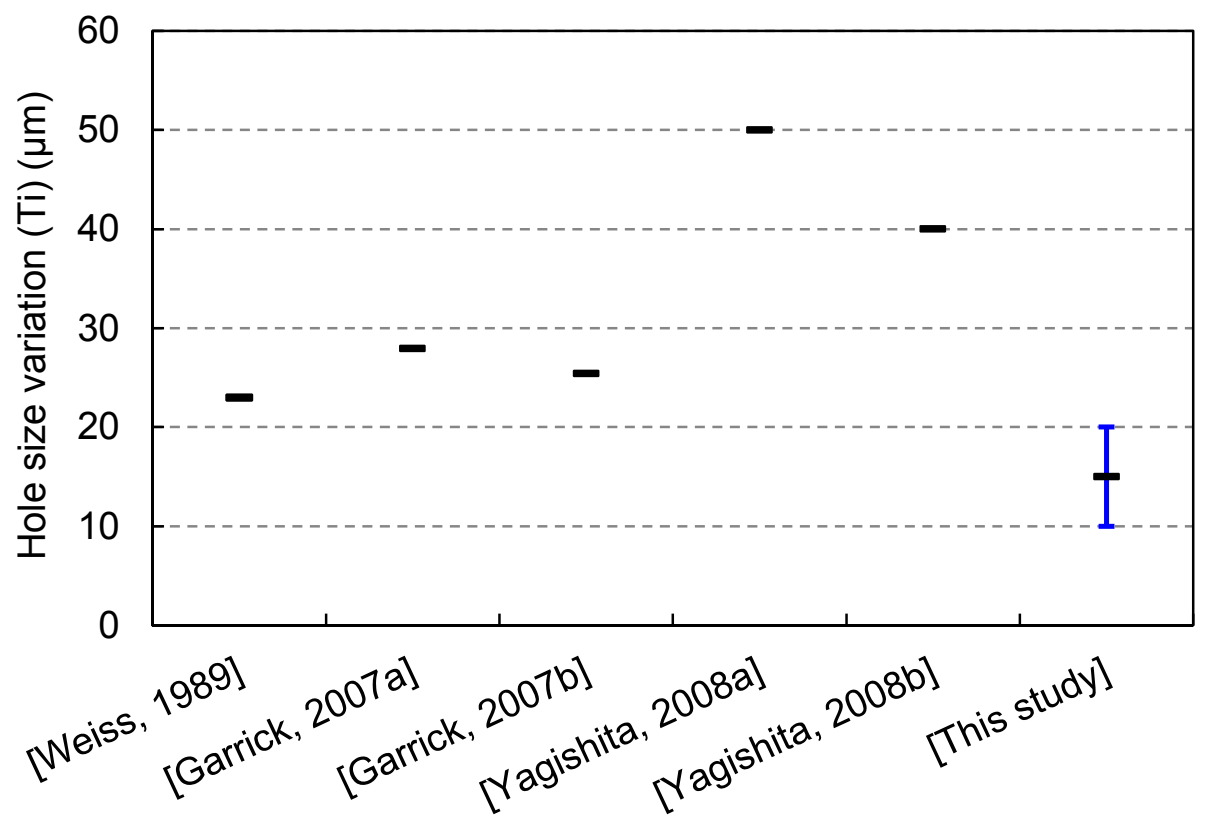

Reference

(b) For Ti

Figure 17 Comparison of hole size variation. 


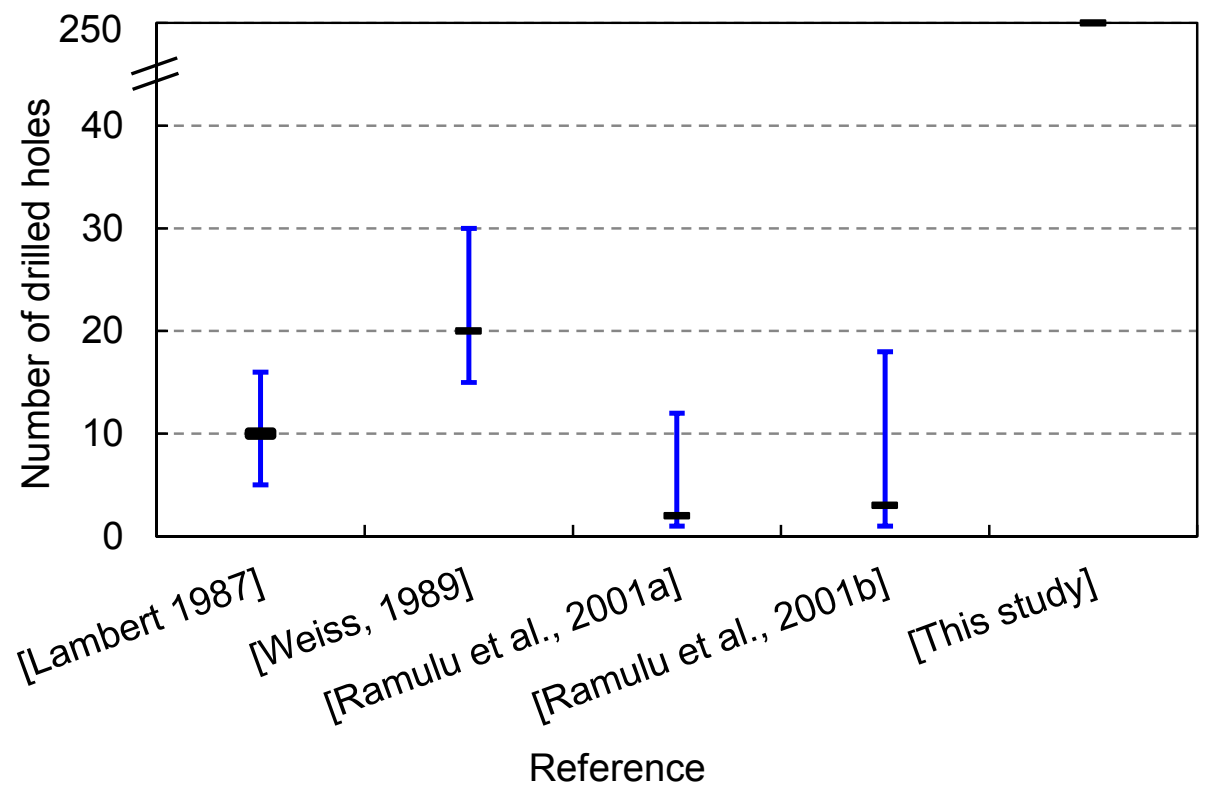

Figure 18 Comparison of tool life. 


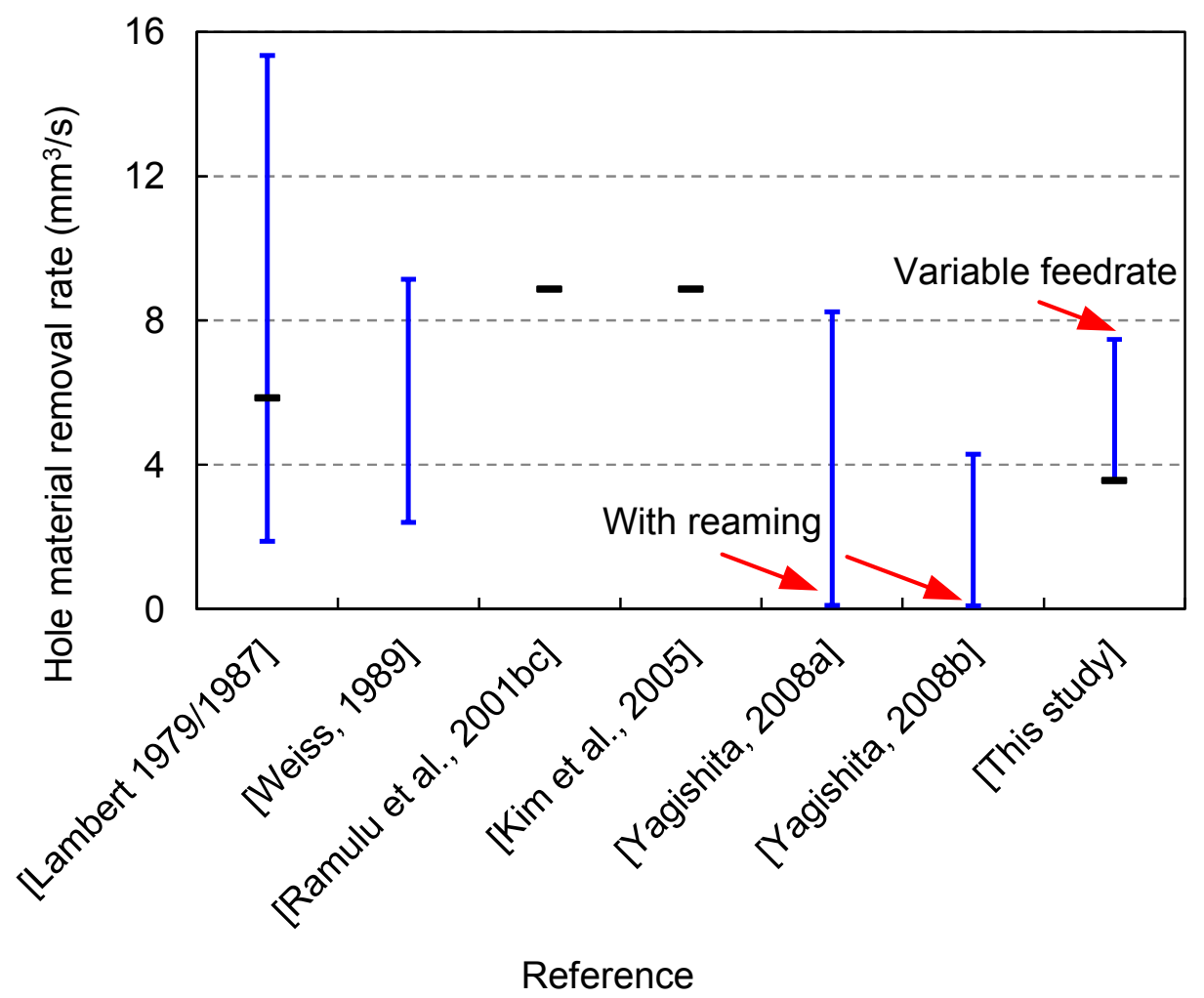

Figure 19 Comparison of cutting rate (hole material removal rate). 